\title{
Taxonomic relationships among the taxa in the Candida guilliermondii complex, as revealed by comparative electrophoretic karyotyping
}

\author{
Feng-Yan Bai, Hui-Yan Liang and Jian-Hua Jia \\ Author for correspondence: Feng-Yan Bai. Tel: +86106255 5692. Fax: +861062560912. \\ e-mail: baify@sun.im.ac.cn
}

Systematic Mycology and Lichenology Laboratory, Institute of Microbiology, Chinese Academy of Sciences, Beijing 100080, China

\begin{abstract}
Electrophoretic karyotypes of 15 type strains of the taxa in the Candida guilliermondii complex including Candida fukuyamaensis Nakase et al. and Candida xestobii Yarrow et S. A. Meyer were comparatively analysed by using the CHEF (contour-clamped homogeneous electric field) method of PFGE. Eighteen strains (isolated from various natural sources in China) which were originally identified as $\mathbf{C}$. guilliermondii by conventional methods were also included. Six electrophoretic karyotype groups were recognized among the strains compared. The following type strains were grouped together with the type strains of C. guilliermondii (Castellani) Langeron et Guerra and Pichia guilliermondii Wickerham: Blastodendrion arztii Ota, Blastodendrion krausi Ota, Candida amidovorans Balloni et al., C. guilliermondii var. japonica Sugiyama et Goto, Candida mamillae S. Goto, Candida parapsilosis (Ashford) Langeron et Talice var. tokyoensis Suzuki et al., C. parapsilosis var. tuxtlensis Herrera et al. and six Chinese strains. The type strain of Torulopsis kestonii Scarr et Rose was classified into the group together with the type strain of Candida fermentati (Saito) Bai and seven Chinese strains. The group represented by the type strain of $C$. fukuyamaensis included five other strains isolated in China. The type strains of Candida xestobii, C. guilliermondii var. carpophila Phaff et M. W. Miller and Trichosporon appendiculare Batista et al. were separated into three different groups, respectively. Taxonomic relationships among the taxa studied are discussed.
\end{abstract}

Keywords: Candida guilliermondii, Candida fermentati, Candida fukuyamaensis, Candida xestobii, electrophoretic karyotype

\section{INTRODUCTION}

Candida guilliermondii (Castellani) Langeron et Guerra is a common species in both natural and clinical environments. Since its first description as Endomyces guilliermondii by Castellani (1912), a considerable number of new species and varieties with phenotypic characteristics similar to those of $C$. guilliermondii have been described. These taxa were listed in a series of monographs on yeast taxonomy as synonyms of C. guillermondii or its teleomorph Pichia guilliermondii Wickerham (Diddens \& Lodder, 1942; Lodder \& Kreger-van Rij, 1952; van Uden \& Buckley, 1970; Barnet et al., 1983, 1990; Meyer et al., 1984, 1998).

Abbreviation: CHEF, contour-clamped homogeneous electric field.
Bai (1996) used DNA base composition and electrophoretic karyotyping to demonstrate that one of the synonyms, Torula fermentati Saito, represented a species distinct from C. guilliermondii. Consequently, a new combination, Candida fermentati (Saito) Bai, was proposed. Since $C$. fermentati and $C$. guilliermondii were indistinguishable by phenotypic criteria, the taxonomic status of the synonyms of $C$. guilliermondii that were not employed by Bai (1996) remained to be clarified.

San Millán et al. (1997) investigated isoenzyme and randomly amplified polymorphic DNA profiles of clinical isolates of $C$. guilliermondii, including the type strains of all synonyms of the species. In addition to confirming $C$. fermentati as a distinct species, their data implied that $C$. guilliermondii was still a heterogeneous species since additional groups were recognized. Kurtzman \& Robnett (1997) predicted that $C$. 
Table 1. Comparison of strains of Candida guilliermondii and related taxa

${ }^{\mathrm{T}}$, Type strain; AS, Institute of Microbiology, Academia Sinica, Beijing, China; CBS, Centraalbureau voor Schimmelculture, Delft, The Netherlands; JCM, Japan Collection of Microorganisms, The Institute of Physical and Chemical Research, Japan.

\begin{tabular}{|c|c|c|c|c|}
\hline Group & Strain & Taxon & Origin & $\begin{array}{c}\text { Size of } \\
\text { chromosomal } \\
\text { DNA (Mb) }\end{array}$ \\
\hline \multirow[t]{15}{*}{ I } & $\mathrm{JCM} 1539^{\mathrm{T}}$ & Candida guilliermondii & Sputum & $0 \cdot 45-2 \cdot 17$ \\
\hline & CBS $2030^{\mathrm{T}}$ & Pichia guilliermondii & Frass & $0 \cdot 45-2 \cdot 17$ \\
\hline & CBS $2024^{\mathrm{T}}$ & Blastodendrion krausi & Ulcer (horse) & $0 \cdot 45-2 \cdot 19$ \\
\hline & CBS $2083^{T}$ & Blastodendrion arztii & Blood & $0 \cdot 45-2 \cdot 17$ \\
\hline & CBS $6021^{\mathrm{T}}$ & $\begin{array}{l}\text { Candida guilliermondii var. } \\
\text { japonica }\end{array}$ & Soil & $0 \cdot 44-2 \cdot 17$ \\
\hline & CBS $6557^{\mathrm{T}}$ & $\begin{array}{l}\text { Candida parapsilosis var. } \\
\text { tuxtlensis }\end{array}$ & Maize dough & $\begin{array}{l}0 \cdot 45-2 \cdot 17 \\
\quad(2 \cdot 23)\end{array}$ \\
\hline & CBS $7099^{\mathrm{T}}$ & Candida mamillae & Nursing bottle & $0 \cdot 44-2 \cdot 17$ \\
\hline & CBS $7232^{\mathrm{T}}$ & Candida amidovorans & Soil & $0 \cdot 45-2 \cdot 17$ \\
\hline & CBS 8105 & $\begin{array}{l}\text { Candida parapsilosis var. } \\
\text { tokyoensis }\end{array}$ & Unknown & $0 \cdot 45-2 \cdot 17$ \\
\hline & AS 2.1660 & & Soil & $0 \cdot 45-2 \cdot 17$ \\
\hline & AS 2.1674 & & Laver & $0 \cdot 45-2 \cdot 17$ \\
\hline & AS 2.1684 & & Leaf & $0 \cdot 45-2 \cdot 17$ \\
\hline & AS 2.1685 & & Flower & $0 \cdot 45-2 \cdot 17$ \\
\hline & AS 2.1687 & & Soil & $0 \cdot 45-2 \cdot 17$ \\
\hline & AS 2.1698 & & Mushroom compost & $0 \cdot 46-2 \cdot 17$ \\
\hline II & $\mathrm{JCM} 9569^{\mathrm{T}}$ & Candida xestobii & Beetle & $0 \cdot 53-2 \cdot 22$ \\
\hline III & CBS $5256^{\mathrm{T}}$ & $\begin{array}{l}\text { Candida guilliermondii var. } \\
\text { carpophila }\end{array}$ & Appendix (human) & $0 \cdot 69-2 \cdot 07$ \\
\hline \multirow[t]{6}{*}{ IV } & JCM 9396 & Candida fukuyamaensis & Pond water & $0 \cdot 68-2 \cdot 02$ \\
\hline & AS 2.1678 & & Slime flux of tree & $0 \cdot 68-2 \cdot 04$ \\
\hline & AS 2.1688 & & Ladybird & $0 \cdot 68-2 \cdot 02$ \\
\hline & AS 2.1689 & & Fruit & $0 \cdot 68-2 \cdot 02$ \\
\hline & AS 2.1690 & & Frass & $0 \cdot 68-2 \cdot 02$ \\
\hline & AS 2.1691 & & Slime flux of tree & $0 \cdot 68-2 \cdot 02$ \\
\hline \multirow[t]{9}{*}{$\mathrm{V}$} & CBS $2022^{\mathrm{T}}$ & Candida fermentati & Air & $0 \cdot 96-1 \cdot 77$ \\
\hline & CBS $5674^{\mathrm{T}}$ & Torulopsis kestonii & Air & $0 \cdot 98-1 \cdot 78$ \\
\hline & AS 2.1677 & & Fruit & $1 \cdot 05-1 \cdot 77$ \\
\hline & AS 2.1680 & & Soil & $0 \cdot 95-1 \cdot 77$ \\
\hline & AS 2.1681 & & Flower & $0 \cdot 95-1 \cdot 78$ \\
\hline & AS 2.1682 & & Mulberry fruit & $0 \cdot 94-1 \cdot 76$ \\
\hline & AS 2.1686 & & Soil & $0.94-1 \cdot 77$ \\
\hline & AS 2.1692 & & Jujube fruit & $0 \cdot 95-1 \cdot 77$ \\
\hline & AS 2.1693 & & Orange peel & $0 \cdot 98-1 \cdot 78$ \\
\hline VI & CBS $5265^{\mathrm{T}}$ & Trichosporon appendiculare & Fig wasp & $1 \cdot 20-2 \cdot 23$ \\
\hline
\end{tabular}

fukuyamaensis Nakase et al. and C. xestobii Yarrow et S. A. Meyer were conspecific with $C$. guilliermondii on the basis of their similar or identical nucleotide sequences in the large-subunit rRNA gene region D1/D2.

In recent years, electrophoretic karyotyping has been increasingly employed in yeast systematics. Though chromosomal length polymorphisms were observed in some yeast species (Boekhout et al., 1993), a remarkable correlation between identical or similar karyotypes and high DNA homologies was shown among several species of Candida and other yeast genera (Lee et al., 1994, 1998; Vallini et al., 1997; Phaff et al., 1998). In the present study, we comparatively analysed the chromosomal DNA banding profiles of type strains of all the taxa that were considered or suspected to be synonymous with $C$. guilliermondii. The strains isolated from natural sources in China and which were originally identified as $C$. guilliermondii by conventional methods were also included. Taxonomic relationships among the taxa concerned were suggested on the basis of their electrophoretic karyotypes. 

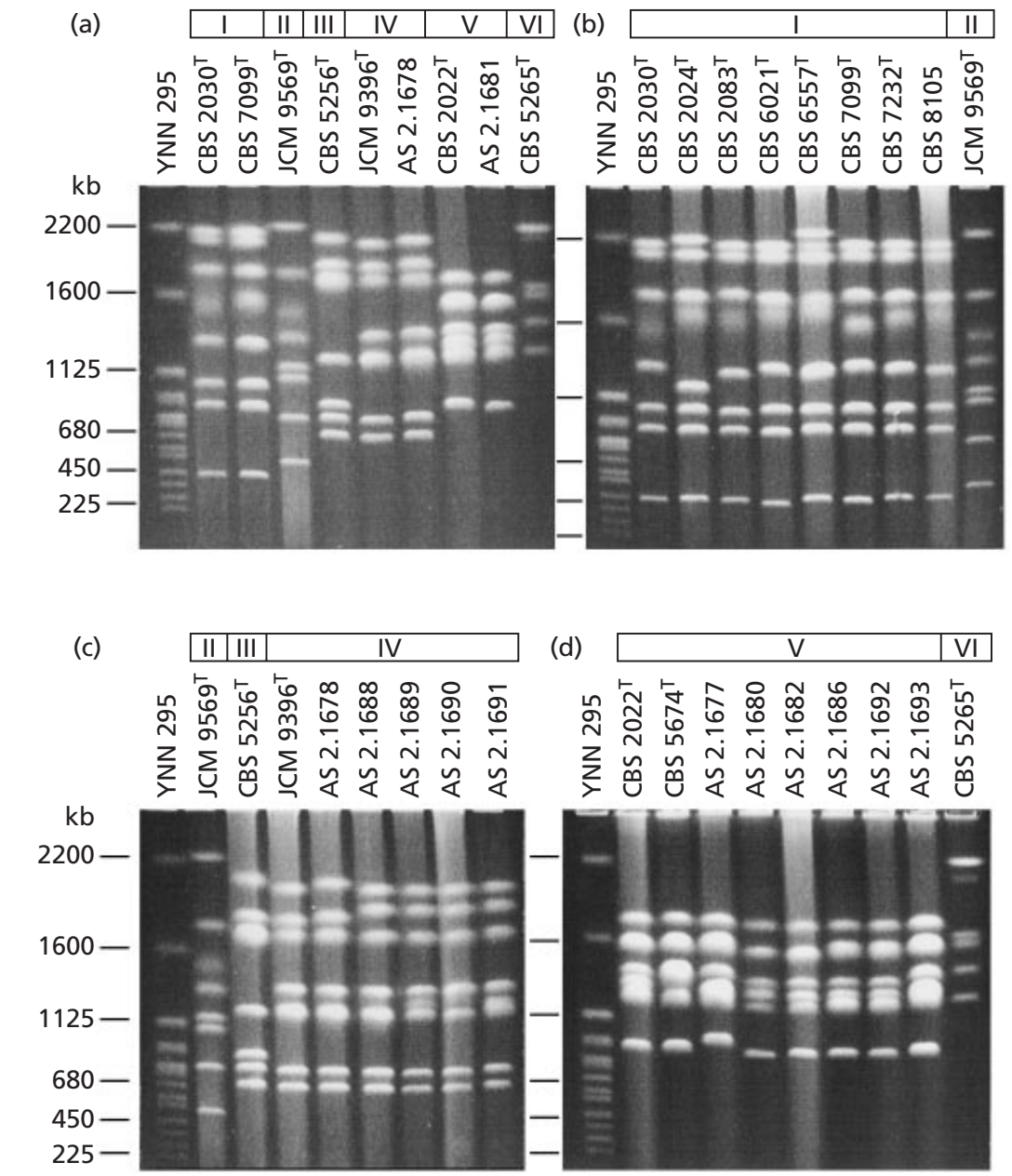

(d) \begin{tabular}{|l|l|}
\hline $\mathrm{V}$ & $\mathrm{VI}$ \\
\hline
\end{tabular}
Fig. 1. Electrophoretic karyotypes of the strains in the Candida guilliermondii complex. (a) Comparison among representative strains of the six groups; (b) comparison between the strains in groups I and II; (c) comparison among the strains in groups II, III and IV; (d) comparison between the strains in groups $\mathrm{V}$ and $\mathrm{VI}$.

\section{METHODS}

Organisms and conventional identification. The strains employed are listed in Table 1. Type strains of the taxa studied were obtained from the CBS (Centraalbureau voor Schimmelculture), Delft, The Netherlands and the JCM (Japan Collection of Microorganisms), The Institute of Physical and Chemical Research (RIKEN), Japan. The strains isolated from natural sources in China were characterized using the methods described by van der Walt \& Yarrow (1984) and were identified according to Meyer et al. (1984).

Preparation of chromosomal DNA and PFGE. Intact yeast chromosomal DNA was prepared for PFGE by using a modified version of the method of Schwartz \& Cantor (1984): yeast cells were grown overnight in $5 \mathrm{ml}$ YPD broth ( $1 \%$ yeast extract, $1 \%$ peptone, $2 \%$ dextrose, all $\mathrm{w} / \mathrm{v}$ ) on a rotary shaker (180 r.p.m.) at $25^{\circ} \mathrm{C}$, harvested with a refrigerated centrifuge and then washed twice with $50 \mathrm{mM}$ EDTA (pH 8.0). Pellets were resuspended in 300-400 $\mu \mathrm{l} \mathrm{SPG}$ buffer [10 mM NaH${ }_{2} \mathrm{PO}_{4}$ in $50 \%$ (v/v) glycerol, pH 6.2]. A $50 \mu \mathrm{l}$ aliquot of the cell suspension was mixed with $25 \mu \mathrm{l}$ Lyticase (Sigma) solution (1000 units $\mathrm{ml}^{-1}$ in SPG) and incubated at $40{ }^{\circ} \mathrm{C}$ for $3-5 \mathrm{~min}$. The preparation was then gently mixed with $225 \mu \mathrm{l}$ molten $1 \%$ (w/v) LMP agarose (BRL) in $125 \mathrm{mM}$ EDTA (pH 7.5). The mixture was pipetted into a mould chamber $(20 \times 9 \times 1.2 \mathrm{~mm}$; Bio-Rad $)$. After solidification, the plug was incubated in $2 \mathrm{ml}$ LET buffer
[500 mM EDTA, $10 \mathrm{mM}$ Tris (pH 8.5), 7.5\% (v/v) 2mercaptoethanol] at $37^{\circ} \mathrm{C}$ overnight. After being washed in $50 \mathrm{mM}$ EDTA (pH 8.0), the plug was incubated in $2 \mathrm{ml}$ NDS buffer [500 mM EDTA, $10 \mathrm{mM}$ Tris (pH 8.5), $1 \%$ laurylsarcosine] with $0.5 \mathrm{mg}$ proteinase $\mathrm{K}$ (Merck) $\mathrm{ml}^{-1}$ at $50{ }^{\circ} \mathrm{C}$ for $24 \mathrm{~h}$, then rinsed three times in $50 \mathrm{mM}$ EDTA $(\mathrm{pH} \mathrm{8} \cdot 0)$ and stored in $100 \mathrm{mM}$ EDTA, $10 \mathrm{mM}$ Tris (pH 9.0) at $4{ }^{\circ} \mathrm{C}$.

Chromosomal DNA bands were separated on $0.8 \%$ agarose gels in $0.5 \times \mathrm{TBE}$ buffer in contour-clamped homogeneous electric field (CHEF) electrophoresis apparatus (CHEF-DR II; Bio-Rad). Electrophoresis was performed at $150 \mathrm{~V}$ for $24 \mathrm{~h}$ with a 100-200 s ramping switch interval and then at $100 \mathrm{~V}$ for $30 \mathrm{~h}$ with a $300-400 \mathrm{~s}$ ramping switch interval. The temperature of the running buffer was maintained at $12-14{ }^{\circ} \mathrm{C}$. After electrophoresis the gel was stained in ethidium bromide solution $\left(0.5 \mu \mathrm{g} \mathrm{m}^{-1}\right)$ for $30 \mathrm{~min}$, destained in distilled water and imaged under UV light (302 $\mathrm{nm}$ ) with the UVP's GDS 5000 gel documentation system. Saccharomyces cerevisiae (YNN 295) chromosomal DNA (Bio-Rad) was used as the marker.

\section{RESULTS}

The CHEF electrophoretic karyotypes of a total of 33 strains of the $C$. guilliermondii complex and related species were determined. Six groups were recognized among these strains. The group including the type 


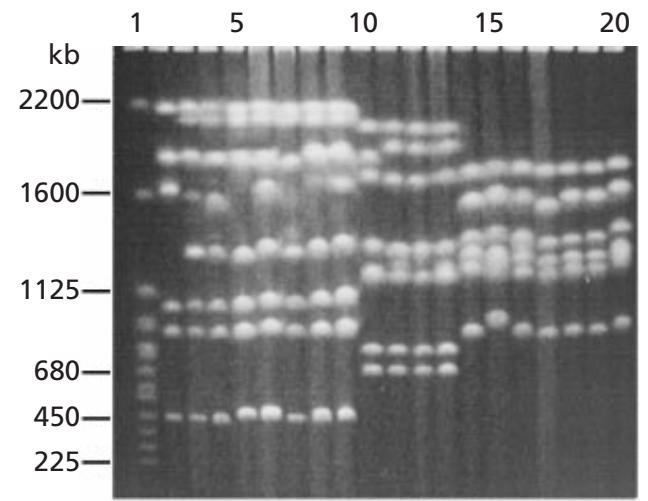

Fig. 2. Electrophoretic karyotypes of the strains in the Candida guilliermondii complex isolated from natural sources in China. Lane 1, YNN 295; lanes 2-9, C. guilliermondii strains JCM 1539', CBS 2030 ${ }^{\top}$, AS 2.1660, AS 2.1674, AS 2.1684, AS 2.1685, AS 2.1687 and AS 2.1698, respectively; lanes 10-13, Candida fukuyamaensis strains JCM 9396 ${ }^{\top}$, AS 2.1689, AS 2.1690 and AS 2.1691, respectively; lanes 14-20, Candida fermentati strains CBS 2022 ${ }^{\top}$, AS 2.1677, AS 2.1680, AS 2.1682, AS 2.1686, AS 2.1692 and AS 2.1693, respectively.

strains of $C$. guilliermondii and $P$. guilliermondii was designated as group I. The other groups were designated as groups II-VI in decreasing order of chromosomal DNA-banding-pattern similarity to group I. The karyotypes of representative strains of the six groups were compared, as shown in Fig. 1(a).

The following type strains were included, along with the type strains of C. guilliermondii (JCM 1539 $)$ and P. guilliermondii (CBS 2030 ${ }^{\mathrm{T}}$ ), in group I: Blastodendrion arztii $\mathrm{Ota}\left(\mathrm{CBS} 2083^{\mathrm{T}}\right)$, Blastodendrion krausi Ota (CBS 2024 ${ }^{\mathrm{T}}$ ), Candida amidovorans Balloni et al. (CBS $7232^{\mathrm{T}}$ ), Candida guilliermondii var. japonica Sugiyama et Goto (CBS 6021 ${ }^{\mathrm{T}}$ ), Candida mamillae S. Goto (CBS $7099^{\mathrm{T}}$ ), Candida parapsilosis var. tuxtlensis Herrera et al. $\left(\mathrm{CBS} 6557^{\mathrm{T}}\right)$, the authentic strain (CBS 8105) of C. parapsilosis (Ashford) Langeron et Talice var. tokyoensis Suzuki et al. and six Chinese strains. Most of the strains in this group contained eight chromosomal DNA bands in their electrophoretic karyotypes, with molecular sizes ranging from approximately 0.45 to $2.17 \mathrm{Mb}$ (Figs $1 \mathrm{~b}$ and 2). No bands were found at positions representing 1.15$1.25 \mathrm{Mb}$ and $1.80 \mathrm{Mb}$ for JCM $1539^{\mathrm{T}}\left(=\mathrm{CBS} 566^{\mathrm{T}}\right)$, the type strain of C. guilliermondii (Fig. 2). Strain CBS $6557^{\mathrm{T}}$, the type strain of C. parapsilosis var. tuxtlensis, contained one additional band representing a molecular size larger than 2.20 Mb (Fig. 1b).

Group II included a single strain, JCM $9569^{\mathrm{T}}$, the type strain of Candida xestobii. Eight chromosomal DNA bands with molecular sizes ranging from 0.53 to $2.22 \mathrm{Mb}$ were resolved. The pattern was similar to that for group I but could be easily differentiated from the latter. The bands representing $0 \cdot 45,0 \cdot 90,1 \cdot 10,2 \cdot 08$ and $2 \cdot 17 \mathrm{Mb}$, shared by the strains in group I, were not found in group II (Fig. 1a, b).
Group III was also composed of a single strain, CBS $5256^{\mathrm{T}}$, the type strain of C. guilliermondii var. carpophila Phaff et M. W. Miller. Its karyotype contained seven chromosomal DNA bands with molecular sizes ranging from 0.69 to $2.07 \mathrm{Mb}$ (Fig. 1a, c). Group IV consisted of the type strain of C. fukuyamaensis, JCM $9396^{\mathrm{T}}$, and five other strains isolated in China. Seven to eight bands in the $0.68-2.02 \mathrm{Mb}$ size range were found in their chromosomal DNA banding profiles (Figs 1c and 2).

Group III and group IV were similar in their chromosomal DNA banding patterns in that they contained a similar number of bands over a similar size range. In view of the fact that strain CBS $5256^{\mathrm{T}}$ contained a $0.93 \mathrm{Mb}$ band that was absent from all the strains of group IV and that every strain in group IV contained a $1.30 \mathrm{Mb}$ band that was absent from strain CBS $5256^{\mathrm{T}}$ (Fig. 1c), we tentatively classified strain CBS $5256^{\mathrm{T}}$ as representing a separate group.

The type strain of Torulopsis kestonii Scarr et Rose was grouped together with the type strain of $C$. fermentati in group V. A total of seven Chinese strains fell into this group. This group could be easily distinguished from all the other ones. The electrophoretic karyotypes of the strains in this group contained five to six bands with molecular sizes ranging from approximately 0.9 to $1.8 \mathrm{Mb}$ (Figs 1d and 2).

The type strain of Trichosporon appendiculare Batista et al., CBS 5265 $5^{\mathrm{T}}$, was found to have a unique karyotype. In the present study, six chromosomal DNA bands with molecular sizes ranging from 1.20 to $2.23 \mathrm{Mb}$ were resolved (Fig. 1a, d). However, its obviously much heavier density compared to other bands in the same lane suggests that the band at the $2.23 \mathrm{Mb}$ position may contain more than one chromosomal DNA molecule not resolved under the electrophoresis conditions employed in the present study. The unresolved DNA molecules may be larger than $2 \cdot 23 \mathrm{Mb}$ in size.

\section{DISCUSSION}

In recent years, we have accumulated hundreds of Candida strains isolated from various natural sources in China. A considerable number of them were identified as $C$. guilliermondii by conventional methods commonly employed in yeast taxonomy (van der Walt \& Yarrow, 1984). After separating C.fermentati from C. guilliermondii on the basis of the type strain of Torula fermentati Saito and three of the Chinese strains (Bai, 1996), we analysed the chromosomal DNA banding patterns of the remaining 18 C. guilliermondii strains isolated in China. As a result, three distinct groups were recognized (Fig. 2). Six of the strains were included in the C. guilliermondii group, seven were included in the $C$. fermentati group and the remaining five strains were included in the Candida fukuyamaensis group. This result suggests that $C$. fermentati is a common species in nature as well as in clinical 
environments, as demonstrated by San Millán et al. (1997). Furthermore, the data obtained indicate that the species $C$. fukuyamaensis is not uncommon in nature, as are $C$. guilliermondii and $C$. fermentati. In view of the results of electrophoretic karyotyping, each of the three species, C. guilliermondii, C. fermentati and C. fukuyamaensis, represents a genetically homogeneous population, since the chromosomal DNA banding profiles of individual strains with different origins in the same species are either very similar or identical.

The following taxa were confirmed as synonymous with $C$. guilliermondii on the basis of the similarities in their chromosomal DNA banding profiles: $B$. arztii, $B$. krausi, C. amidovorans, C. guilliermondii var. japonica, C. mamillae, $C$. parapsilosis var. tokyoensis and $C$. parapsilosis var. tuxtlensis. This result conformed with the conclusion of San Millán et al. (1997), who included these taxa in the same group with the type strain of $C$. guilliermondii on the basis of isoenzymeand randomly amplified polymorphic DNA profiles. The synonymy of $T$. kestonii with $C$. fermentati demonstrated in the present study also conforms with the work of San Millán et al. (1997).

The type strain of Trichosporon appendiculare was grouped with the type strains of $C$. fermentati and $T$. kestonii by San Millán et al. (1997). However, we found that the chromosomal DNA banding pattern of the former differed markedly from those of the latter two and all the other strains in group II (Fig. 1d). In our opinion, $T$. appendiculare should be treated as representing a separate species rather than as a synonym of $C$. fermentati.

Kurtzman \& Robnett (1997) indicated that the nucleotide sequences in the large-subunit rDNA region D1/D2 of C. fukuyamaensis and C. xestobii were identical and that they differed from that of $C$. guilliermondii by only one nucleotide. Consequently, they predicted that the three species were conspecific. However, their prediction is not supported by the present study. The difference between C. guilliermondii and C.fukuyamaensis in electrophoretic karyotyping is clearly shown in Fig. 2, as discussed above. The similarity value of $35-42 \%$ obtained from a reciprocal DNA-DNA reassociation experiment with the two species indicates their distinction at species level (Nakase et al., 1994).

The karyotype of $C$. xestobii differed notably from that of C. fukuyamaensis (Fig. 1c). Although the chromosomal DNA banding profile of $C$. xestobii was relatively similar to that of $C$. guilliermondii, it was easy to differentiate the former from the latter (Fig. 1b). In view of the homogeneous karyotypes of the 15 strains in the C. guilliermondii group and the six strains in the C. fukuyamaensis group, it seems reasonable to separate $C$. xestobii from the former two species.

The taxonomic position of $C$. guilliermondii var. carpophila remains to be clarified. Although Meyer \&
Phaff (1972) showed that there was a significant degree of DNA-DNA relatedness between the type strain of C. guilliermondii var. guilliermondii and two strains of the variety carpophila, the type strain of the latter differed markedly from all the strains of the $C$. guilliermondii group in electrophoretic karyotyping. This result conforms with the results of San Millán et al. (1997), who separated C. guilliermondii var. carpophila from the C. guilliermondii var. guilliermondii group on the basis of different isoenzyme patterns.

C. guilliermondii var. carpophila may not be conspecific with $C$. guilliermondii var. guilliermondii, as discussed above; however, its relationship with $C$. fukuyamaensis should be investigated further. Although we tentatively allocated C. guilliermondii var. carpophila to a different group from that of $C$. fukuyamaensis, the similarities in chromosomal DNA size range and banding pattern between these two groups indicated a close genetic relationship.

Among the taxa studied, $C$. xestobii can be distinguished not only by electrophoretic karyotyping, but also by conventional methods. C. xestobii can only ferment glucose slowly, while all the other taxa compared with it can strongly ferment glucose and sucrose, can slowly or weakly ferment raffinose and can (in most cases) slowly or weakly ferment galactose. C. xestobii also differs from the others by its inability to use D-arabinose or D-mannitol as the sole source of carbon. Furthermore, the type strain of $C$. xestobii cannot grow at temperatures above $30^{\circ} \mathrm{C}$, whereas all the other strains studied can grow at $37^{\circ} \mathrm{C}$ or above.

However, the remaining taxa of this study are indistinguishable according to the conventional criteria commonly employed in yeast taxonomy (van der Walt \& Yarrow, 1984; Barnett et al., 1990; Yarrow, 1998). Further study is required in order to differentiate these genetically separate taxa in practice. Although Nakase et al. (1994) indicated that C. fukuyamaensis could be distinguished from $C$. guilliermondii by means of a soluble starch-assimilation test (the former gives a positive result but the latter is negative), none of the five Chinese strains in the C. fukuyamaensis group could assimilate soluble starch. This implies that the phenotypic demarcation of the species C. fukuyamaensis requires revision.

\section{ACKNOWLEDGEMENTS}

We thank Dr D. Yarrow (Yeast Division, CBS, Delft, The Netherlands) and Dr T. Nakase (Japan Collection of Microorganisms, The Institute of Physical and Chemical Research, Japan) for kindly supplying type strains. We also thank Professor Ru-Yong Zheng (Institute of Microbiology, Chinese Academy of Sciences, Beijing, China) for her invaluable advice on the manuscript. This research was supported by grant no. 39700001 from the National Natural Science Foundation of China (NSFC) and, in part, by the Special Coordination Funds of the Science and Technology Agency of the Japanese Government for the Asian Network on Microbial Researches. 


\section{REFERENCES}

Bai, F.-Y. (1996). Separation of Candida fermentati comb. nov. from Candida guilliermondii by DNA base composition and electrophoretic karyotyping. Syst Appl Microbiol 19, 178-181.

Barnett, J. A., Payne, R. W. \& Yarrow, D. (1983). Yeasts: Characteristics and Identification. Cambridge: Cambridge University Press.

Barnett, J. A., Payne, R. W. \& Yarrow, D. (1990). Yeasts: Characteristics and Identification, 2nd edn. Cambridge: Cambridge University Press.

Boekhout, T., Renting, M., Scheffers, W. A. \& Bosboom, R. (1993). The use of karyotyping in the systematics of yeasts. Antonie Leeuwenhoek 63, 157-163.

Castellani, A. (1912). Observations on the fungi found in tropical bronchomycosis. Lancet i, 13-15.

Diddens, H. A. \& Lodder, J. (1942). Die Anaskosporogenen Hefen, II Hälfte. Amsterdam: North-Holland.

Kurtzman, C. P. \& Robnett, C. J. (1997). Identification of clinically important ascomycetous yeasts based on nucleotide divergence in the $5^{\prime}$ end of the large-subunit (26S) ribosomal DNA gene. $J$ Clin Microbiol 35, 1216-1223.

Lee, C.-F., Lee, F.-L. \& Hsu, W.-H. (1994). Synonymy of Candida methylica with Candida boidinii and of Candida methanolophaga with Candida succiphila. Int J Syst Bacteriol 44, 839-841.

Lee, F.-L., Fu, H.-M. \& Hsu, W.-H. (1998). DNA hybridization and electrokaryotype study of some Candida species. Int $J$ Syst Bacteriol 48, 1463-1466.

Lodder, J. \& Kreger-van Rij, N. J. W. (1952). The Yeasts, a Taxonomic Study. Amsterdam: North-Holland.

Meyer, S. A. \& Phaff, H. J. (1972). DNA base composition and DNA-DNA homology studies as tools in yeast systematics. In Yeast Models in Science and Technics. Proceedings of the Specialized Symposium on Yeasts, Smolenice, pp. 375-387. Edited by A. Kocková-Kratochvílová \& E. Minarik. Bratislava: Slovak Academy of Science.
Meyer, S. A., Ahearn, D. G. \& Yarrow, D. (1984). Candida Berkhout. In The Yeasts, a Taxonomic Study, 3rd edn, pp. 585-844. Edited by N. J. W. Kreger-van Rij. Amsterdam: Elsevier.

Meyer, S. A., Payne, R. W. \& Yarrow, D. (1998). Candida Berkhout. In The Yeasts, a Taxonomic Study, 4th edn, pp. 454-573. Edited by C. P. Kurtzman \& J. W. Fell. Amsterdam: Elsevier.

Nakase, T., Suzuki, M., Takashima, M., Hamamoto, M., Hatano, T. \& Fukui, S. (1994). A taxonomic study on cellulolytic yeasts and yeast-like microorganisms isolated in Japan. I. Ascomycetous yeast genera Candida and Williopsis, and a yeast-like genus Prototheca. J Gen Appl Microbiol 40, 519-531.

Phaff, H. J., Vaughan-Martini, A. \& Starmer, W. T. (1998). Debaryomyces prosopidis sp. nov., a yeast from exudates of mesquite trees. Int J Syst Bacteriol 48, 1419-1424.

San Millán, R. M., Wu, L.-C., Salkin, I. F. \& Lehmann, P. F. (1997). Clinical isolates of Candida guilliermondii include Candida fermentati. Int J Syst Bacteriol 47, 385-393.

Schwartz, D. C. \& Cantor, C. R. (1984). Separation of yeast chromosome-sized DNAs by pulsed field gradient gel electrophoresis. Cell 37, 67-75.

van Uden, N. \& Buckley, H. (1970). The genus Candida Berkhout. In The Yeasts, a Taxonomic Study, 2nd edn, pp. 893-1087. Edited by J. Lodder. Amsterdam: North-Holland.

Vallini, G., Frassinetti, S. \& Scorzetti, G. (1997). Candida aquaetextoris sp. nov., a new species of yeast occurring in sludge from textile industry wastewater treatment plant in Tuscany, Italy. Int J Syst Bacteriol 47, 336-340.

van der Walt, J. P. \& Yarrow, D. (1984). Methods for the isolation, maintenance, classification and identification of yeasts. In The Yeasts, a Taxonomic Study, 3rd edn, pp. 45-104. Edited by N. J. W. Kreger-van Rij. Amsterdam: Elsevier.

Yarrow, D. (1998). Methods for the isolation, maintenance and identification of yeasts. In The Yeasts, a Taxonomic Study, 4th edn, pp. 77-100. Edited by C. P. Kurtzman \& J. W. Fell. Amsterdam: Elsevier. 